\title{
A Comprehensive Survey on Use of Soft Computing and Optimization Techniques for Load Frequency Control
}

\author{
Yogesh Prajapati ${ }^{1}$, Vithal Kamat ${ }^{2}$, Jatin Patel $^{3}$, Rahul Kher ${ }^{4}$ * \\ ${ }^{1}$ Department of Electrical Engg, BVM Engg College, Vallabh Vidyanagar, India \\ ${ }^{2}$ Baroda Electric Meters, Vithal Udyognagar, India \\ ${ }^{3}$ Department of Electrical Engg, G H Patel College of Engg \& Tech, Vallabh Vidyanagar, India \\ ${ }^{4}$ Department of Electronics \& Communication Engg, G H Patel College of Engg \& Tech, Vallabh Vidyanagar, India \\ Email address: \\ yrp_ee@yahoo.in (Y. Prajapati),vk@kvah.in(V. Kamat),jjpatelgcet@gmail.com (J. Patel), rahul2777@gmail.com (R. Kher) \\ ${ }^{*}$ Corresponding author
}

\section{To cite this article:}

Yogesh Prajapati, Vithal Kamat, Jatin Patel, Rahul Kher. A Comprehensive Survey on Use of Soft Computing and Optimization Techniques for Load Frequency Control. Journal of Electrical and Electronic Engineering. Special Issue: Soft Computing Methods for Electrical and Electronics Engineering Applications. Vol. 8, No. 2, 2020, pp. 64-70. doi: 10.11648/j.jeee.20200802.13

Received: April 20, 2020; Accepted: May 27, 2020; Published: June 20, 2020

\begin{abstract}
Load frequency control (LFC) is one of the most profitable ancillary services of power system market presently. The main goal of LFC is to reduce zero steady-state error for frequency deviations. In the present review paper of LFC problem, worldwide history of various types of controllers, control strategy, smart techniques and methodologies which are implemented and which can be implemented at generation, transmission and distribution areas of a power system. Moreover, ABT mechanism in India is implemented in 2002 to regulate grid frequency. Out of this in deregulated power system energy storage with the potential of different types of energy storage at distribution area in the power system has been highlighted. In a smart grid due to intermittent nature of the renewable energy sources (wind and solar), unpredictable daily and seasonal variations there may be an imbalance between supply and demand which results in deviations in the grid frequency. To eliminate the problem of LFC Electrical energy storage (EES) is technologies are listed. LFC problem with different soft computing techniques such as Genetic Algorithm (GA), Neural Network (NN), Fuzzy Logic (FG), Particle Swarm Optimization (PSO), Bacterial Foraging Optimization (BFP), Tabu Search Algorithm (TSA) has been carried out. This literature review will help the new researcher to give the guideline to work in the area of load frequency control.
\end{abstract}

Keywords: Automatic Generation Control (AGC), Load Frequency Control, Restructured Power System, Distributed Energy Storage (DES)

\section{Introduction}

Today, the present grid is a smart grid. In a large-scale power system, many types of power plants are connected to meet the load demand. It becomes essential to maintain deviations in the frequency and tie-line power against load disturbance when more than one power systems are connected. The frequency of the power system deviates, due to the sudden load change. The nature of renewable energy sources is uneven, which causes frequency and power deviations too. A lot of research has been carried on Load Frequency Control (LFC) problem in conventional power system as well as deregulated power system. Study based on LFC problem with different soft computing techniques such as Genetic Algorithm (GA), Neural Network (NN), Fuzzy Logic (FG), Particle Swarm Optimization (PSO), Bacterial Foraging Optimization (BFP), Tabu Search Algorithm (TSA) has been carried out. Also, many researchers have tried to solve LFC problem using AC-DC tie line, Flexible AC Transmission System (FACTS), considering communication delay, different learning techniques and different types of Distributed Energy Storage System (DESS). Further study on communication delay, renewable energy sources penetration and need for electrical storage with different types of storages have also been carried out. Storage potential in BESS as centralized and decentralized distributed electrical vehicles has found 
tremendous potential to regulated frequency. Presently, in deregulated power system different competitive companies sell unbundled power at lower rates. Also, a lot of ancillary services are introduced like voltage and frequency regulation, load balancing, peak power savings, etc. Load frequency Control (LFC) as ancillary services are becoming much more significant today. In this study, the types of power system models for LFC with various control strategies are outlined.

\section{Single and Multi-Area Conventional Power System}

The LFC problem in a single area power system for its dynamic performance and delay margin by using Lyapounuv theory based on the dependent criterion and linear matrix inequalities (LMIs) techniques have been represented by Jiangen et al. [1]. Based on the comparative analysis the results for single area power system by consideration of Generation Rate Constraint (GRC) without the controller, full state controller and with optimal output feedback are represented by Singh et. al. [2]. Two area interconnected power system with thermal reheat unit including GRC and Boiler Dynamics has been discussed by Sudha and Santhi [3]. Lili Dong [4] has presented single area thermal power system with reheat, non-reheat and hydraulic unit with its design based on active disturbance rejection control. The simulation results verified the effectiveness of the ADRC, in comparison with an existing Proportional Integral (PI) type controller tuned via Genetic Algorithm Linear Matrix Inequalities (GALMIs). LFC problem with four area power system is presented by Zhou [5]. A detailed structured singular value method for local area robustness analysis and an Eigenvalue method are derived for tie-line robustness analysis. Fuzzy Cmeans clustering has been used by considering GRC by Sudha et. al [6]. LFC problem by consideration of time delay is presented by Dey et. al. [7]. LFC with a time-varying delay with LMI technique and PI controller has been presented by Chidambaram [8]. AGC with output vector control feedback theory incorporated with AC / DC-link has been presented by Kumar et. al. [9]. Fatemeh Daneshgar et. al. has presented three area power system with GA based PI controller [10]. LFC problem with redox flow battery has been presented by Chidambaram [11]. Doolla presented LFC problem for a single area hydropower system with multi pipe scheme in hydropower plant [12]. Kalyan Chatterjee et. al. [13] have discussed an effect of Battery Energy Storage in two area deregulated power system. Decentralize LFC for multi-area power system have presented by Muthana et. al. [14]. Hierarchical optimal robust load frequency control is represented by Rahmani and Sadati [15]. Hemeida [16] discussed multi-area LFC problem with comparative study of fuzzy-based Super Magnetic Energy Storage (SMES), PI base SMES and without SMES. Hooshmand et. al. has presented a multi-machine system with PID based FLC [17]. Bhatt et. al. [18] investigated multi area LFC problem with coordinated control of SMES and Thyristor Controlled Phase
Shifter (TCPS). Two area power system with dead band as a nonlinearity has been analyzed by Tsay [19]. Sliding Mode based LFC problem has been solved for multi area power system by Vrdoljak et. al. [20]. Multi area power system with area participation factor by applying GA based reinforced learning algorithm have been represented by Daneshfar and Bevrani [21]. LFC in Multi area power system with Time delay and its real time implementation has been discussed by Bevrani et. al. [22]. Autonomous controller with single phase inverter to control active and reactive power due to large disturbances has been presented by Salamah et. al. [23]. The LFC problem in two area power system has been considered with GRC and DB and its solution is proposed using hybrid evolutionary fuzzy PI controller by Juang and Lu [24]. Multi area LFC had been analyzed using GA based fuzzy logic by $\mathrm{Du}$ and Li [25].

\section{Different Soft Computing Techniques Applied in LFC}

\subsection{Genetic Algorithm}

The GA is a one of the optimization techniques based on the operation of natural genetics. GA is largely applied to solve complex nonlinear optimization problems such as AGC. Comparative study between GA as an optimization tool and conventional Matrix - Riccati based optimal control is presented by Ghosal [26] et. al. Successful results for the optimized gain value are achieved using GA tool. PID controller gain tuned by GA with successful results is presented the authors [26]. The superiority of GA-SA technique against GA method for off-nominal and optimal PID gains is presented by the same authors [26-27]. Robust LFC design method based on $\mathrm{H} \infty$ control with Linear Matrix Inequalities (LMI) techniques and GA tuned PI controller are proposed by Hasanovic et. al. [28]. Result revealed that robustness of performance of GALMI is almost same as that of the robust $\mathrm{H} \infty$ controllers. A comparative study based on a hybrid fuzzy proportional integral (FPI) controller and hybrid GA-PSO optimization techniques is presented by Juang and $\mathrm{Lu}$ [29]. Least square algorithm using GA for achieving real time parameters for optimal value of gain for LFC is shown by Chang-Chien [30]. Interconnected hydro-thermal power system, a continuous discrete mode for AGC framework is presented by Vijay and Jena [31]. GA tuned PI controller is used for the BESS as EVs with grid connected RES by Biswas and Bera [32]. The basic GA application in a digital computer is identified with hydro-generator plant by Womiac et. al. [33]. GA tuned fuzzy gain scheduling for LFC is shown by Juang et. al. for the power system [34]. For LFC intelligent controller as a GA is proposed by Dang Prasert et. al. [37]. Different approach to control generator output power and frequency using fuel rack position controls the speed of generator is shown by Shayeghi et. al. [38]. To optimize PID parameters under sliding mode, GA tool is used for the solution of LFC in multi area power system [39]. Pingkang et. al. have presented the control parameter optimization using GA technique for 
robust decentralized frequency stability [40]. In a deregulated power system with three area, LFC solution is proposed by Ngamroo et. al. [41] a new decentralized robust control strategy based on the mixed $\mathrm{H} 2$ / $\mathrm{H} \infty$ control technique. Chang et. al. [42] have presented gain scheduling of PI controller using GA based fuzzy logic rule-based system and presented the load frequency control for a multi-area interconnected power system. The variable structural controller (VSC) feedback gain tuned by GA has been presented by Chang et. al. [43] to solve LFC problem. For tuning trial and error method is followed by the authors. An adaptive optimal gain scheduling approach to the Load Frequency Control (LFC) problem has been proposed by Al-Hamouz et. al. [44]. Aditya [46] presents a design of GA for two area hydropower system model.

\subsection{Neural Networks}

Neural Network (NN) works on prediction-based theory and corrects nonlinear relationship between input and output. Francoise Beaufays [47] presents a nonlinear application of $\mathrm{NN}$ in power system for LFC. The NN is investigated as an intelligent controller in conjunction with standard adaptive LFC by Birch et al. [48]. Automatic LFC using NN is developed to control steam and water flow by Chaturvedi et. al. [49]. The flow controller regulates the speed of the generator, which helps to regulate frequency and generator output power. Authors [50] have considered nonlinearities such as dead band and rehear effect in two area power system for LFC problem. Effectiveness of $\mathrm{NN}$ controller is presented to regulate frequency deviations. AGC based on reinforcement learning approach is presented by Ahamed et al. [51]. Talaq et al. proposed training-based controller for better performance of adaptive controller as compared to a neural network based adaptive scheme [52].

\subsection{Fuzzy Logic}

Fuzzy logic can solve the LFC problem based on knowledge and experience. Superiority of fuzzy logic by a comparative study based on fuzzy logic and the classical integral controller is presented by Indulkar and Raj [53]. With the nonlinearity such as dead band and Generation Rate Constraint (GRC), LFC problem is simulated in four area power system by Chang and $\mathrm{Fu}$ [54] and better results are obtained using fuzzy gain scheduling of PI controller. Fuzzy rule based tabu search algorithm for LFC problem is presented by Denna et. al. [55]. LFC problem in three equal area power system having radian and ring connections and solution by self-adjusting fuzzy gain scheduling scheme have been presented by Ertugrul et. al. [56]. Authors have presented two area thermal power system with fuzzy controller [57]. Sinha et al. [58] presented GA based PSO tuned fuzzy controller for AGC in three area power system.

\subsection{Particle Swarm Optimization (PSO)}

Particle swarm optimization can be used on the concept of swarm intelligence. Aqeel S. Jaber has presented Particle
Swarm Optimization (PSO) technique to solve the LFC problem by tuning the fuzzy logic input and output parameter [60]. For a hydropower plant, PSO and fuzzy logic with sliding mode control are presented by Houshmand [61]. PSO technique for HVDC tie line connected in parallel with the AC tie line is presented by Selvakumaran et. al. [62]. Bhatt et. al. [63] have presented hybrid particle swarm optimization for determining optimal PID gains for LFC in four-area power system shaving deregulation environments. Based on adaptive neuro-fuzzy inference and PSO control scheme LFC dynamic and steady response is simulated by Hosseini and Etemadi [64]. For two area power system, LFC based on adaptive weighted particle swarm optimization with multi objective PID controller is presented by Sharifi et. al. [65].

\subsection{Bacterial Foraging Optimization Algorithm (BFOA)}

BFOA theory is motivated by nature and operated by four processes namely swarming, reproduction, elimination and dispersal. Bacterial foraging is another modern meta-heuristic technique which is used to find a global minimum of complex optimization problem. Performances of several integer order (IO) controllers have been evaluated and are compared with FOPID controller for AGC with multi-area thermal systems with reheat turbines and appropriate GRC by Debbarama [66]. Optimization for the governor speed regulation parameter (Ri) and frequency bias parameter $(\mathrm{Bi})$ is carried out. Moreover, superiority of BFO against GA and classical optimization techniques by gain tuning for the integral controller is presented [68]. A similar approach of using BFO algorithm to tune controller gain was also presented by Ali et. al. [67] with the superiority of proposed controller over conventional area controller and GA optimized controller.

\subsection{Tabu Search Algorithm (TSA)}

The TSA starts from some initial feasible solution and attempts to determine a better solution in the manner of a hill-climbing algorithm. TSA uses past step to create a better solution. Saravuth et. al. have presented a new optimization technique of a fuzzy logic based proportional integral (FLPI) load frequency controller by the multiple tabu search (MTS) algorithm for the improvement in learning of fuzzy rule by using heuristic symbolic approach [59]. Maurizio Denna et al. have presented an approach for the automatic definition of fuzzy rules in the fuzzy controller based on TSA for the improvement in learning of fuzzy rule by using heuristic symbolic Meta rules [55].

\subsection{Other Optimization Control Techniques}

By considering active power flow, a fuzzy rule-based system was formed to select the best controllers, their movements and step size by Lenoir et. al. [69]. M. Farahani presented the method of optimized PID gains by the lozi map-based chaotic algorithm (LCOA) to solve the LFC problem [70]. LFC problem solution with Differential evolution algorithm, which optimized the PID gain is presented by Sahu et. al. [71]. It is observed that the proposed 
controllers are quite robust for a wide range of the system parameters and operating load conditions from their nominal values. Rout et. al. [72] have presented the design and performance analysis of Proportional-Integral (PI) controller based on Differential Evolution (DE) algorithm for AGC operation. Mohanty et. al. [73] presented controller parameters tuning of Differential Evolution (DE) algorithm for LFC. Results of comparative analysis between DE, I, PI and PID are also presented. Goshaidas et al. [74] have presented a solution for LFC in a single area thermal power system with robust controller based on the Riccati-equation. Robust controller for LFC problem in a deregulated two area thermal power systems by using an m-synthesis approach is given by Bevrani [75]. A decentralized $\mathrm{H} \infty$ damping control design based on the mixed-sensitivity formulation in the LMI framework is reported by Chaudhari and Pal [76]. The robust design of the PI controller for LFC problem in three area interconnected power system based on $\mathrm{H} \infty$ static output feedback control technique is solved by using an iteratively developed LMI [77]. Robust analysis and design of load frequency controller is described in [78].

\section{Conclusion}

An effort has been put for a critical literature review of applications of different soft computing techniques for load frequency control (LFC) problem. LFC under conventional power system and restructured power system with grid-connected and in an isolated mode have been discussed. From the literature survey, it has been observing that worldwide lot of researcher has put their effort to solve the LFC problem in a conventional and restructured power system. The repeated AGC operation of the governor will increase wear and tear loss. Also, the dynamic response of the governor is slow. Lots of research exist on LFC problem in deregulated power system with energy storage and found lot of potential battery energy storage system (BESS). It can provide fast and active power compensation and improve the performance of load frequency control.

\section{References}

[1] Jiangen L, Yao W, Wu Q H, Wen JY, Cheng S J, "Delay-Dependent Stability for Load Frequency Control with Constant and Time-Varying Delays", IEEE Transactions On power systems; vol. 27, ISS. 2, 2012.

[2] Singh Parmar K P, Majhi S, Kothari D P, "Load Frequency Control of a Realistic Power System with Multi-Source Power Generation", International Journal of Electrical Power and Energy Systems, vol. 42, ISS. 1, pp. 426-433, Nov 2012

[3] Sudha K R, Santhi R V," Load Frequency Control of An Interconnected Reheat Thermal System Using Type-2 Fuzzy System Including SMES Units", Electrical Power and Energy Systems, vol. 43, ISS. 1, pp. 1383-1392, Dec 2012.

[4] Dong L, Zhang Y, Gao Z, "A Robust Decentralized Load Frequency Controller for Interconnected Power Systems", ISA Transaction, vol. 51, ISS. 3, pp. 410-419, May 2012
[5] Tanw, Zhou H, "Robust Analysis of Decentralized Load Frequency Control for Multi-Area Power Systems", Electrical Power and Energy Systems, vol. 43, ISS. 1, pp. 996-1005, Dec 2012.

[6] Sudha K R, Raju V B, Sekhar A C, "Fuzzy C-Means Clustering for Robust Decentralized Load Frequency Control of Interconnected Power System with Generation Rate Constraint”, Electrical Power and Energy Systems, vol. 37, ISS 1, pp. 58-66, May 2012.

[7] Rajeev Dey, Ghosh S, Ray Rakshita, "Hळ Load Frequency Control of Interconnected Power Systems with Communication Delays", Electrical Power and Energy Systems, vol. 42, ISS. 1, pp. 672-684, Nov 2012.

[8] Chidambaram IA, Paramasivam B, "Control Performance Standards-Based Load-Frequency Controller Considering Redox Flow Batteries Coordinate with Interline Power Flow Controller", Journal of Power Sources, vol. 219, ISS. 1, pp. 292-304, Dec 2012.

[9] I Braheem, Kumar P, Hassan N, Nizamuddin, "Sub-Optimal Automatic Generation Control of Interconnected Power System Using Output Vector Feedback Control Strategy", Electric Power Components and Systems, vol. 40, ISS. 9, pp. 977-994, Jun 2012.

[10] Fatemeh Daneshgar, Hassan Bevrani, "Multi Objective Design of Load Frequency Control Using Genetic Algorithms", Electrical Power and Energy Systems vol. 42, pp. 257-263, 2012.

[11] I. A. Chidambaram, B. Paramasivam, "Control Performance Standards Based Load-Frequency Controller Considering Redox Flow Batteries Coordinate with Interline Power Flow Controller", Journal of Power Sources, vol. 219, pp. 292-304, 2012.

[12] S. Doolla, T. S. Bhatti and R. C. Bansal, "Load Frequency Control of An Isolated Small Hydro Power Plant Using Multi-Pipe Scheme", Electric Power Components and Systems, vol. 39, ISS. 1, pp. 46-63, DOI: 10.1080/15325008.2010.513362, 2010.

[13] Kalyan Chatterjee, "Effect of Battery Energy Storage System on Load Frequency Control Under Deregulation", International Journal of Emerging Electric Power Systems: vol. 12: ISS. 3, Article 2. DOI: 10.2202/1553-779X.2700, 2013.

[14] Muthana T. Alrifai, Mohamed F. Hassan, Mohamed Zribi, "Decentralized Load Frequency Controller for A Multi-Area Interconnected Power System", Electrical Power and Energy Systems vol. 33, pp. 198-209. 2011.

[15] M. Rahmani and N. Sadati, "Hierarchical Optimal Robust Load-Frequency Control for Power Systems", IET Gener. Transm. Distrib., vol. 6, ISS. 4, Pp. 303-312, Doi: 10.1049/Iet-Gtd.2011.0544, 2012.

[16] Ashraf Mohamed Hemeida, "A Fuzzy Logic Controlled Superconducting Magnetic Energy Storage, SMES Frequency Stabilizer", Electric Power Systems Research vol. 80, pp. 651656, 2010.

[17] A. Khodabakhshian, R. Hooshmand, "A New PID Controller Design for Automatic Generation Control of Hydro Power Systems", Electrical Power and Energy Systems vol. 32, pp. 375-382, 2010. 
[18] Pragnesh Bhatt, S. P. Ghoshal B, Ranjit Roy, "Load Frequency Stabilization by Coordinated Control of Thyristor Controlled Phase Shifters and Supper Conducting Magnetic Energy Storage for Three Types of Interconnected Two-Area Power Systems", Electrical Power and Energy Systems vol. 32, pp. 1111-1124, 2010.

[19] Tain-Sou Tsay, "Load-Frequency Control of Interconnected Power System with Governor Backlash Nonlinearities", Electrical Power and Energy Systems vol. 33, pp. 1542-1549, 2011.

[20] K. Vrdoljak, N. Peri'c, I. Petrovi'c, “Sliding Mode Based Load-Frequency Control in Power Systems", Electric Power Systems Research vol. 80, pp. 514-527, 2010.

[21] F. Daneshfar H. Bevrani, "Load-Frequency Control: A GA-Based Multi-Agent Reinforcement Learning”, IET Gener. Transm. Distrib., vol. 4, ISS. 1, pp. 13-26, Doi: 10.1049/Iet-Gtd.2009.0168, 2010

[22] Hassan Bevrani, Takashi Hiyama, "On Load-Frequency Regulation with Time Delays: Design and Real-Time Implementation", IEEE Transactions on Energy Conversion, vol. 24, vo. 1, Mar 2009.

[23] A. M. Salamah, S. J. Finney and B. W. Williams, "Autonomous Controller for Improved Dynamic Performance of AC Grid, Parallel-Connected, Single-Phase Inverters", IET Gener. Transm. Distrib., vol. 2, ISS. 2, pp. 209 - 218, 2008.

[24] C.-F. Juang and C.-F. Lu, "Load-Frequency Control by Hybrid Evolutionary Fuzzy PI Controller", IEEE Proc. Gener. Transm. Distrib., Vol. 153, No. 2, March 2006.

[25] Xiuxia Du and Pingkang Li, "Fuzzy Logic Control Optimal Realization Using GA for Multi-Area AGC Systems", International Journal of Information Technology Vol. 12 No. 7 2006.

[26] S. P. Ghoshal, S. K. Goswami, "Application of GA Based Optimal Integral Gains in Fuzzy Based Active Power-Frequency Control of Non-Reheat and Reheat Thermal Generating Systems", Electric Power Systems Research vol. 67, pp. 79-88, Doi: 10.1016/S0378-7796(03)00087-7, 2003.

[27] S. P. Ghoshal, "Application Of GA/GA-SA Based Fuzzy Automatic Generation Control of a Multi-Area Thermal Generating System", Electric Power Systems Research vol. 70, pp. 115-127, DOI: 10.1016/J.Epsr.2003.11.013, 2004.

[28] Dulpichet Rerkpreedapong and Amer Hasanovic, "Robust Load Frequency Control Using Genetic Algorithms and Linear Matrix Inequalities", IEEE Transactions on Power Systems, vol. 18, no. 2, 0885-8950/03, May 2003.

[29] C. F. Juang And C.-F. Lu, "Load-Frequency Control by Hybrid Evolutionary Fuzzy PI Controller", IEE Proc.-Gener. Transm. Distrib., vol. 153, no. 2, Doi: 10.1049/Ip-Gtd:20050176, March 2006.

[30] L.-R. Chang-Chien, "Online Estimation of System Parameters for Artificial Intelligence Applications to Load Frequency Control”, IET Gene. Trans. Distr., vol. 5, ISS. 8, pp. 895-902, Doi: 10.1049/Iet-Gtd.2010.0654, 2011.

[31] Mokenapalli. Vijay, Debashisha Jena, "A Continuous-Discrete Mode of Optimal Control of AGC for Multi Area Hydrothermal System using Genetic Algorithm”, 2012 International Conference on Computing, Communication and Applications, Feb 2012.
[32] P Biswas, P Bera, "GA Application to Optimization of AGC in Two Area Power System Using BES", International Conference on Communications, Devices and Intelligent Systems (CODIS), 10.1109/CODIS.2012.6422208, Dec 2012.

[33] Chnstopher A, L. and Womiak, P. "Hydro generator System Identification Using A Simple Genetic Algorithm", IEEE Transactions on Energy Conversion, Vol. 12, No. 1, 0885-8969/97, Mar 1997.

[34] Chia-Feng Juang and Chun-Feng Lu, "Power System Load Frequency Control by Genetic Fuzzy Gain Scheduling Controller", Journal of The Chinese Institute of Engineers, vol. 28, ISS. 6, pp. 1013-1018, DOI: 10.1080/02533839.2005.9671077, Mar 2011.

[35] Y. L. Karnavas, D. P. Papadopoulos, "AGC For Autonomous Power System Using Combined Intelligent Techniques", Electric Power Systems Research vol. 62, pp. 225-239, 2002.

[36] Y. L. Abdel Magid, M. M. Dawoud "Optimal AGC Tuning with Genetic Algorithms", Electric Power Systems Research, vol. 38, pp. 231-238, PII S0378-7796(96)01091-7, 1997.

[37] Pataya Dangprasert and Vichit Avatchanakorn, "Genetic Algorithms Based on An Intelligent Controller", Expert Systems with Applications, vol. 10, no. 314, pp. 465-470, 1996.

[38] Hossein Shayeghi, Heidar Ali Shayanfar, "Design of Decentralized Robust LFC In A Competitive Electricity Environment", Journal of Electrical Engineering, vol. 56, no. 9-10, pp. 225-236, 2005.

[39] Chia-Feng Hang and Chun-Feng Lu, "Power System Load Frequency Control with Fuzzy Gain Scheduling Designed by New Genetic Algorithms “, Doi: 10.1109/FUZZ.2002.1004961, May 2002.

[40] Li Pingkang, Zhu Hengjun, Li Yuyun, "Genetic Algorithm Optimization for AGC of Multi-Area Power Systems", Proceedings of ECC TENCON' 02, DOI: 10.1109/TENCON.2002.1182689, Oct 2002.

[41] Issarachai Ngamroo, Jarurote Tippayachai, Sanchai Dechanupaprittha, "Robust Decentralized Frequency Stabilizers Design of Static Synchronous Series Compensators by Taking System Uncertainties into Consideration", Electrical Power and Energy Systems vol. 28, pp. 513-524, DOI: 10.1016/J.Ijepes.2006.01.005, 2006.

[42] Nikzad Mehdi et al. "Comparison of Artificial Intelligence Methods for Load Frequency Control Problem", Australian Journal of Basic and Applied Sciences, vol. 4, ISS. 10: 4910 $21,2010$.

[43] C. S. Chang A, Weihul FU A and Fushuan WEN, "Load Frequency Control Using Genetic Algorithm Based Fuzzy Gain Scheduling of PI Controllers", Electric Machines \& Power Systems, vol. 26: 1, pp. 39-52, DOI: 10.1080/07313569808955806, May 2007

[44] Z. M. Al-Hamouz, H. N. Al-Duwaish, "A New Load Frequency Variable Structure Controller Using Genetic Algorithms", Electric Power Systems Research vol. 55, pp. 16, PII: S0378-7796(99)00095-4, 2000.

[45] Adel Abdennour, "Adaptive Optimal Gain Scheduling for the Load Frequency Control Problem", Electric Power Components and Systems, vol. 30: 1, pp. 45-56, DOI: 10.1080/153250002753338391, Nov. 2010. 
[46] Aditya, "Design of Load Frequency Controllers Using Genetic Algorithm for Two Area Interconnected Hydro Power System", Electric Power Components and Systems, vol. 31: 1, pp. 81-94, DOI: $10.1080 / 15325000390112071$, June 2010.

[47] Fransoise Beaufays, Youssef Abdel Magid And Bernrd Widrow, "Application of Neural Networks to Load-Frequency Control in Power Systems", Neural Networks, vol. 7, ISS. 1, pp. 183-194, 1994

[48] A. P. Bid, A. T. Sapclt Jr, CS Bzvcm, "An Enhanced Neural Network Load Frequency Control Technique", International Conference on Control - Control '94, DOI: 10.1049/cp:19940167, Mar 1994.

[49] D. K. Chaturvedi, P. S. Satsangi, P. K. Kalra," Load Frequency Control: A Generalized Neural Network Approach", Electrical Power and Energy Systems, vol. 21, pp. 405-415, PII: S0142-0615(99)00010-1, 1999.

[50] Aysen Demiroren, Neslihan S. Sengor, H. Lale Zeynelgil, "Automatic Generation Control by Using ANN Technique", Electric Power Components and Systems, vol. 29, ISS. 10, pp. 883-896, Nov 2010.

[51] T. P. Imthias Ahamed, P. S. Nagendra Rao, P. S. Sastry, "A Reinforcement Learning Approach to Automatic Generation Control", Electric Power Systems Research vol. 63, pp. 9-6, PII: S 0378 - 7796 (02) 00088 - 3, ELSEVIER, 2002.

[52] Jawad Talaq And Fadel Al-Basri, "Adaptive Fuzzy Gain Scheduling for Load Frequency Control", IEEE Transactions on Power Systems, Vol. 14, No. 1, February 1999

[53] C. S. Indulkar and Baldev Raj, "Application of Fuzzy Controller to Automatic Generation Control, Electric Machines \& Power Systems", 23: 2, 209-220, DOI: 10.1080/07313569508955618, April, 2007.

[54] C. S. Chang, Weihui Fu, "Area Load Frequency Control Using Fuzzy Gain Scheduling of PI Controllers", Electric Power Systems Research, pp. 145-152, S. A. PII SO378-7796, 1997.

[55] Maurizio Denna, Giancarlo Mauri, And Anna Maria Zanaboni, "Learning Fuzzy Rules with Tabu Search-An Application to Control”, IEEE Transactions on Fuzzy Systems, vol. 7, no. 2, Apr 1999

[56] Ertugrul CAM İlhan Kocaarslan, Turkey, "Load-Frequency Control in Two Area Power System", Teknoloji, vol. 7, ISS. 2, pp. 197-203, 2004.

[57] Ertugrul Cam, Ilhan Kocaarslan, "Load Frequency Control in Two Area Power Systems Using Fuzzy Logic Controller, Energy Conversion and Management", vol. 46, pp. 233-243, ELSEVIER, 2005.

[58] S. K. Sinha, R. N. Patel, "Application of GA and PSO Tuned Fuzzy Controller for AGC Of Three Area ThermalThermal-Hydro Power System", International Journal of Computer Theory and Engineering, Vol. 2, No. 2, 1793-820, April, 2010.

[59] Saravuth Pothiya, Issarachai Ngamroo, Suwan Runggeratigul, And Prinya Tantaswadi, "Design of Optimal Fuzzy Logic Based PI Controller Using Multiple Tabu Search Algorithm for Load Frequency Control", International Journal of Control, Automation, And Systems, vol. 4, no. 2, pp. 155-164, Apr 2006.

[60] Aqeel S. Jaber, A. Z. Ahmad, Ahmed N Abdalla, "An Investigation of Scaled-FLC Using PSO For Multi-Area Power
System Load Frequency Control", Energy and Power Engineering, vol. 5, pp. 458-462 DOI: 10.4236/Epe.2013.54B088, July 2013.

[61] R. Houshmand, M. Ataei And A. Zargari, "A New Fuzzy Sliding Mode Controller for Load Frequency Control of Large Hydropower Plant Using Particle Swarm Optimization Algorithm and Kalman Estimator", Euro. Trans. Electr. Power, vol. 22, ISS. 6, pp. 812-830, Jul 2011

[62] S. Selvakumaran, S. Parthasarathy, R. Karthigaivel, V. Rajasekaran, "Optimal Decentralized Load Frequency Control in a Parallel AC-DC Interconnected Power System through HVDC Link using PSO Algorithm", Energy Proceeding vol. 14, pp. 1849-1854, 2012

[63] Praghnesh Bhatt, Ranjit Roy, S. P. Ghoshal, "Optimized Multi Area AGC Simulation in Restructured Power Systems", Electrical Power and Energy Systems vol. 32, pp. 311-322, 2010.

[64] S. H. Hosseini, A. H. Etemadi, Adaptive "Neuro-Fuzzy Inference System Based Automatic Generation Control", Electric Power Systems Research vol. 78, pp. 1230-1239, DOI 10.1016/J.Epsr.2007.10.007, 2008.

[65] A. Sharifi, K. Sabahi, M. Aliyari Shoorehdeli, M. A. Nekoui, M. Teshnehlab, "Load Frequency Control In Interconnected Power System Using Multi-Objective PID Controller", IEEE Conference On Soft Computing In Industrial Applications (Smcia/08), Muroran, Japan, Doi: 10.1109/SMCIA.2008.5045963, Jun 2008,

[66] Sanjoy Debbarma, Lalit Chandra Saikia, Nidul Sinha, "AGC Of A Multi-Area Thermal System Under Deregulated Environment Using A Non-Integer Controller", Electric Power Systems Research, vol. 95, pp. 175-183, 0378-7796, 2013.

[67] E. S. Ali, S. M. Abd-Elazim, "Bacteria Foraging Optimization Algorithm Based Load Frequency Controller for Interconnected Power System", Electrical Power and Energy Systems, vol. 33, pp. 633-638, DOI: 10.1016/J.Ijepes.2010.12.022, 2011.

[68] Janardan Nanda, S. Mishra, Lalit Chandra Saikia, “Application of Bacterial Foraging-Based Optimization Technique in Multiarea Automatic Generation Control”, IEEE Transactions on Power Systems, Vol. 24, No. 2, 0885-8950, May 2009.

[69] Laurent Lenoir, Innocent Kamwa, "Overload Alleviation with Preventive-Corrective Static Security Using Fuzzy Logic", IEEE Transactions on Power Systems, Vol. 24, No. 1, February 2009 ,

[70] M. Farahani S. Ganjefar M. Alizadeh, "PID Controller Adjustment Using Chaotic Optimization Algorithm for Multi-Area Load Frequency Control", IET Control Theory, vol. 6, ISS. 13, pp. 1984-1992, Doi: 10.1049/Iet-Cta.2011.0405, Apr 2012.

[71] Rabindra Kumar Sahu, Sidhartha Panda, Umesh Kumar Rout, "De Optimized Parallel 2-Dof Pid Controller for Load Frequency Control of Power System with Governor Dead-Band Nonlinearity", Electrical Power and Energy Systems vol. 49, pp. 19-33, 2013.

[72] Umesh Kumar Rout, Rabindra Kumar Sahu, Sidhartha Panda, "Design and Analysis of Differential Evolution Algorithm Based Automatic Generation Control for Interconnected Power System", Ain Shams Engineering Journal, vol. 4, ISS. 3, pp. 409-421, Sep 2013. 
[73] Banaja Mohanty, Sidhartha Panda, P. K. Hota, "Controller Parameters Tuning of Differential Evolution Algorithm and Its Application to Load Frequency Control of Multi-Source Power System", Electrical Power and Energy Systems vol. 54, pp. 7785, 0142-0615, 2014.

[74] Goshaidas Ray A, A. N. Prasad B, G. D. Prasad, "A New Approach to the Design of Robust Load-Frequency Controller, For Large Scale Power Systems", Electric Power Systems Research, vol. 51, pp. 13-22, 1999.

[75] Hassan Bevrani, "Robust Load Frequency Controller in a Deregulated Environment: A U-Synthesis Approach", IEEE International Conference on Control Applications, Doi: 10.1109/CCA.1999.806723, Aug 1999.
[76] Balarko Chaudhuri, Bikash C. Pal, Argyrios C. Zolotas, Imad M. Jaimoukha, And Tim C. Green, "Mixed-Sensitivity Approach to Hinf Control of Power System Oscillations Employing Multiple Facts Devices", IEEE Transactions on Power Systems, vol. 18, no. 3, Aug 2003.

[77] Wen Tan, Zhan Xu, "Robust Analysis and Design of Load Frequency Controller for Power Systems", Electric Power Systems Research vol. 79, pp. 846-853, 2009.

[78] Hassan Bevrani, Takashi Hiyama, Yasunori Mitani, "Automatic Generation Control: A Decentralized Robust Approach", Intelligent Automation and Soft Computing", vol. 13, No. 3, pp. 273-287, 2007. 